\title{
Impacts of the teacher professional development program on students' perceptions of the learning climate and life skills \\ Transfer
}

\author{
Okseon Lee ${ }^{\mathrm{a} *}$, Euichang Choi ${ }^{\mathrm{a}}$, Hyukjun Son ${ }^{\mathrm{b}}$, Kihee $\mathbf{J o}^{\mathrm{c}}$, \& Hyunsoo Jung ${ }^{\mathrm{d}}$ \\ ${ }^{a}$ Professor, Department of Physical Education, Seoul National University \\ ${ }^{b}$ Doctoral candidate, Department of Physical Education, Seoul National University \\ ${ }^{c}$ Researcher, Korea Institute for Curriculum and Evaluation \\ ${ }^{d}$ Assistant professor, Cheongju National University of Education
}

\begin{abstract}
The purpose of this study was to investigate the effect of a life skills-centered teacher professional development program on students' perceptions of the learning climate and life skills transfer. Data were collected through a survey of 294 secondary school students $(n=183$, experimental group; $n=111$, control group) by administering the Learning Climate Questionnaire (LCQ) and the Korean Life Skill Transfer Survey (KLSTS) questionnaire. Data were analyzed using SPSS 20.0 and AMOS 21.0. Results showed that there were significant differences in perceptions of the learning climate and life skills transfer between students in the experimental group and those in the control group $(p<.05)$. Findings of the study indicated that a teacher professional development program can influence students' perceptions of the learning climate, especially regarding autonomy, competence, and relatedness, thus promoting life skills development and transfer.
\end{abstract}

Key words: professional development, learning climate, life skills, positive youth development

\section{Introduction}

Recently, positive youth development (PYD) has been the major approach in sport education for adolescents (Holt, 2016), and it is emerging as a core concept in physical education in South Korea, which emphasizes education of the whole person (Choi, 2010; Ministry of Education, 2015). Despite its conceptual

Submitted : 29 May 2020

Revised : 1 September 2020

Accepted : 9 November 2020

Correspondence : okseonlee@snu.ac.kr importance, it is ambiguous how physical education teachers can practically provide a well-rounded education through PYD in their classes; in fact, they are experiencing significant difficulties because of the lack of specific pedagogical methods and strategies (Lee et al., 2018).

One way of implementing PYD is teaching adolescents life skills. Adolescents need these skills and abilities for successful living; furthermore, life skills are expected to be learned through repeated practice, modeling, and feedback in sports (Danish, 1995). Life 
skills such as communication, problem-solving, conflict resolution, and goal-setting can be developed through practice and training in sports circumstances (Gould \& Carson, 2008). Life skills are not automatically acquired by simply participating in sports, rather, they should be taught and practiced (Kerrick, 2015; Walker, Marczak, Blyth, \& Borden, 2005) with clear intentions (Turnnidge, Côté, \& Hancock, 2014). The examples of the programs developed with goals and intentions are GOAL (Danish, Meyer, Mash, Howard, Curl, Brunelle, \& Owens, 1998), a goal-pursuing program; The First Tee (Weiss, 2006), a golf program; and SUPER (Danish, 2002), a program that can be applied to various sports.

Physical education teachers, however, have insufficient knowledge, skills, and strategies regarding how to teach life skills in physical education classes (Lee et al., 2018). For in-service teachers, teacher professional development (PD), which involves activities that enhance their professional competencies for effective teaching practice, is urgently needed (Armour, 2017). Previous literatures showed that traditional, one-shot PD is not effective for changing PE teachers' teaching practice (Armour \& Yelling, 2007). Studies on effective PD program found that it should be on-going, sustained, collaborative, active, interactive and supported with care (Betchel \& O'Sullivan, 2006; Casey, 2013; Parker, Patton, \& Tannehill, 2012). To provide consistent support, PD should provide feedback and follow-up support with teachers for an extended period time (Goodyear, 2017). In addition, participants should be engaged in diverse, active and interactive learning opportunities such as observing other classes, being observed by other teachers, micro-teaching in the gym, and discussion (Murphy \& O'Leary, 2012; Sinelnikov, 2009). Professional development of in-service teachers is drawing academic attention globally because it not only changes teachers' knowledge, skills, and beliefs, but it also ultimately improves students' achievements (Lee et al., 2019).
Therefore, a one-year professional development (PD) program that supports physical education teachers in the effective teaching of life skills was conducted in this study, and differences between students who learned from teachers who participated in the program and teachers who did not were investigated. The PD program was composed of content that guided teachers in developing a supportive classroom climate for students' needs (Ryan \& Deci, 2000), as well as autonomy, competence, and relatedness of students based on the basic needs theory (BNT). The program was in operation for one year through online pre-training, intensive workshops, and monthly meetings. In addition, specific strategies and teaching methods were provided so that the learning climate would promote the development of life skills based on the conceptual model by Hodge et al. (2012), which states that if students' needs are satisfied by continued learning in a needs-supportive climate, the result will be the development of general life skills.

The purpose of this study was to determine if there were differences in students' perceptions of the classroom climate related to life skills and levels of life skills development between students taught by teachers who participated in the PD program for one year and students in the control group. The hypotheses that were established follow. First, perceptions of the classroom climate related to life skills will be different between the students who were taught by teachers participating in the program and students whose teachers were not participating. Second, the level of life skills between students taught by teachers who participated in the program and students whose teachers did not will be different.

\section{Methods}

Professional development program ("Change up!")

The professional development program called Project 
Change Up was designed to provide knowledge and skills with secondary PE teachers for teaching life skills in PE classes. The program was developed through online survey with 251 secondary PE teachers, literature review on effective PE-CPD (O'Sullivan \& Deglau, 2006), two pilot tests with secondary PE teachers, and program optimization based on the feedback from pilot tests (Lee et al., 2019).

The program was implemented for one year from January 2018 to February 2019. It included 10 modules of online pre-training on PE curriculum and life skills approach, 30 hours of intensive workshops on positive youth development theory and practice, and 10 sessions of monthly workshop with participants. The purpose of the online pre-training was to motivate teachers for participating in PD program and also provide background knowledge. The online pre-training included 5-minute video clips with pedagogical cases and provided follow-up discussion guide. The 30 hours of intensive workshop provided theoretical knowledgebase on positive youth development and life skills approach to integrate life skills into competence-based national curriculum, collective lesson planning, micro-teaching experience, and group discussion and reflection. After intensive workshop, all teachers began implementing life skills approach in their schools. During this time, monthly workshops were provided for ten times. The monthly workshop worked as a community of practice by sharing their experiences of life skills implementation, remaining issues and concerns, finding solutions and alternatives, and setting goals for future improvement. Meanwhile, all teacher participants engaged in mobile instant messenger-based chatroom activities in order to share their practice and swift exchange of ideas.

\section{Procedure and participants}

The study was conducted with experimental group of students $(\mathrm{n}=183)$ who learned from six teachers participating in the PD program (“Change Up!") and control group of students $(\mathrm{n}=111)$ who learned from teachers who did not participate in the program attending the same school. The protocol of the study was reviewed and approved by the University's Institutional Review Board. Informed consent was obtained by all participants and their parents or guardians.

Teachers who participated in the PD program conducted physical education classes to foster life skills for one academic year beginning in March 2018. The survey was conducted at the end of the semester in January 2019. Specific demographic characteristics of the subjects are presented in Table 1 and Table 2.

Table 1. Demographic characteristics of teacher participants

\begin{tabular}{cccc}
\hline \hline & Gender & $\begin{array}{c}\text { Years of } \\
\text { experience }\end{array}$ & School level \\
\hline Dongsoo & Male & 17 & High school \\
Yukyung & Female & 19 & Middle school \\
Euijae & Male & 8 & High school \\
Sara & Female & 3 & Middle school \\
Grace & Female & 3 & High school \\
Pyungsuk & Male & 5 & Middle school \\
\hline \hline
\end{tabular}

Table 2. Demographic characteristics of the participants

\begin{tabular}{cccc}
\hline \hline & Item & $\begin{array}{c}\text { Frequency } \\
\text { (n) }\end{array}$ & $\begin{array}{c}\text { Percentage } \\
(\%)\end{array}$ \\
\hline \multirow{2}{*}{ Gender } & Male & 141 & 48 \\
& Female & 153 & 52 \\
\hline \multirow{2}{*}{ School level } & High school & 123 & 41.8 \\
& Middle school & 171 & 58.2 \\
\hline \multirow{3}{*}{ Group } & Experimental & 183 & 62.2 \\
& group & & 37.8 \\
\hline \hline
\end{tabular}

\section{Instruments}

\section{Learning Climate Questionnaire (LCQ)}

To determine the level of subjects' perceptions of classes conducted by physical education teachers, a questionnaire developed by Williams and Deci 
(1996) —also used by Standage, Duda, and Ntoumanis (2005) — was modified and supplemented to fit the purpose of the present study. Two sport pedagogy specialists, three physical education teachers, and one sport psychologist participated in the translation of the questionnaire from English to Korean. Once the translation process was completed, items were reviewed with two professors in sport pedagogy and a questionnaire was created; it contained 24 items and three sub-factors (15 items for autonomy, four items for competence, and five items for relatedness) on a 7-point Likert scale. To test the validity of the scale, a confirmatory factor analysis was conducted and the null hypothesis was rejected with $\chi^{2}=703.804$ and $\mathrm{df}$ $=249(\mathrm{p}<.05)$, but the goodness-of-fit index was acceptable with TLI $=.937$, CFI $=.943$, and RMSEA $=.079$. The internal consistency reliability (Cronbach's $\alpha$ ) of each item was determined to be appropriate for autonomy (.944), competence (.939), and relatedness (.952).

\section{Korean Life Skill Transfer Survey (KLSTS)}

To investigate the level of subjects' life skills transfer, the KLSTS, which is a Korean version of the Life Skills Transfer Survey originally developed by Weiss et al. (2014) was used. It was validated as a Korean version of the life skills transfer questionnaire by Lim T. et al. (2018), and it consists of 38 items and eight sub-factors on a 5-point Likert scale, with the following sub-factors: six items for "Meeting and greeting," four items for "Managing emotions," five items pertaining to "Goal setting," four items related to "Resolving conflicts with friends," four items for "Resolving conflicts with siblings," five items for "Making healthy choices," three items for "Appreciating diversity," and seven items related to "Helping others and getting help." A confirmatory factor analysis was conducted to test the validity of the scale, and the TLI and CFI did not meet the goodness-of-fit index with $\chi^{2}=1423.543(\mathrm{p}<.05), \mathrm{df}=637$, TLI $=.878$, CFI
$=.889$, and RMSEA $=.065$, resulting in deleting items with a factor loading of less than .50. Deleted items were item \#2 of (.220) "Managing emotions," items \#6 (.250) and \#11 (.311) of "Making healthy choices," and item \#16 (.358) of "Helping others and getting help." The second confirmatory factor analysis performed after deleting the four items showed that TLI did not meet the goodness-of-fit index with $\chi^{2}=1086.853(\mathrm{p}<.05)$, $\mathrm{df}=499$, TLI $=.899, \mathrm{CFI}=.911$, and RMSEA $=.063$. Accordingly, the model was modified by accepting the correlation between items 31 (e35) and 37 (e33) of "Helping others and getting help," for which the motivation index was 34.954. The results of the confirmatory factor analysis of the modified model were satisfactory with $\chi^{2}=1049.481(\mathrm{p}<.05)$, df $=498$, TLI $=.906$, CFI $=.916$, and RMSEA $=.061$. The internal consistency reliability (Cronbach's $\alpha$ ) of each item was determined to be appropriate for "Meeting and greeting" (.908), "Managing emotions" (.802), "Goal setting" (.929), "Resolving conflicts with friends" (.847), "Resolving conflicts with siblings" (.877), "Making healthy choices" (.738), "Appreciating diversity"(.765), and "Helping others and getting help" (.886).

\section{Data analyses}

Analyses were performed using SPSS 20.0 and AMOS 21.0 programs as follows. First, a frequency analysis and descriptive statistical analysis were performed to identify the characteristics of subjects and review normality of the main variables. Second, a confirmatory factor analysis and internal consistency reliability assessment were performed to evaluate validity and reliability of the measurement variables for reflecting the concept of latent variables. Third, independent samples $t$-tests were performed to determine differences between the variables of the experimental and control groups. A statistical significance level was set at .05 in the present study. 
Table 3. Students' Perceptions of the Learning Climate for Classes Related to Life Skills

\begin{tabular}{|c|c|c|c|c|c|c|c|}
\hline Variable & Sub-factor & Group & $\mathrm{N}$ & $\mathrm{M}$ & $\mathrm{SD}$ & $\mathrm{t}$ & $\mathrm{p}$ \\
\hline \multirow{6}{*}{$\begin{array}{l}\text { Recognition of the } \\
\text { atmosphere of } \\
\text { classes related to } \\
\text { life skills }\end{array}$} & Autonomy & Experimental group & 183 & 5.20 & 1.042 & \multirow{2}{*}{$5.592 * * *$} & \multirow{2}{*}{.000} \\
\hline & Support & Control group & 111 & 4.55 & .917 & & \\
\hline & Competence & Experimental group & 183 & 5.58 & 1.124 & \multirow{2}{*}{$5.412 * * *$} & \multirow{2}{*}{.000} \\
\hline & Support & Control group & 111 & 4.85 & 1.128 & & \\
\hline & Relatedness & Experimental group & 183 & 5.68 & 1.177 & \multirow{2}{*}{$5.204^{* * *}$} & \multirow{2}{*}{.000} \\
\hline & Support & Control group & 111 & 4.96 & 1.116 & & \\
\hline
\end{tabular}

\section{Results}

Students' perception of a learning climate related to life skills

Independent sample t-tests were performed on 183 students who attended classes of teachers participating in the PD program and 111 students who attended classes of teachers who were not participating to determine differences in students' recognition of the atmosphere of classes related to life skills classes. The results are presented in Table 3. The experimental group scored higher than the control group for all factors pertaining to autonomy support, competence support, and relatedness support, and the differences were statistically significant. This finding appears to indicate that teachers implemented the life skills approach emphasized in the PD program and students recognized the intended atmosphere.

Students' life skills transfer

Scores for the experimental group were higher than for the comparison group according to eight factors (resolving conflicts with friends, resolving conflicts with siblings, appreciating diversity, goal setting, managing emotions, making healthy choices, helping others and getting help, and meeting and greeting), and the differences were statistically significant $(p<.05)$. The results suggest that the continuous participation of teachers in the PD program for one year influenced the development of students' life skills transfer.

Table 4. Students' Life Skills Transfer

\begin{tabular}{|c|c|c|c|c|c|c|c|}
\hline Variable & Sub-factor & Group & $\mathrm{N}$ & M & SD & $\mathrm{t}$ & $\mathrm{p}$ \\
\hline \multirow{16}{*}{$\begin{array}{l}\text { Life skills } \\
\text { development }\end{array}$} & Resolving conflicts & Experimental group & 183 & 3.96 & .703 & \multirow{2}{*}{$5.587 * * *$} & \multirow{2}{*}{.000} \\
\hline & with friends & Control group & 111 & 3.48 & .752 & & \\
\hline & Resolving conflicts & Experimental group & 183 & 3.66 & .862 & \multirow{2}{*}{$3.857 * * *$} & \multirow{2}{*}{.000} \\
\hline & with siblings & Control group & 111 & 3.29 & .769 & & \\
\hline & Appreciating & Experimental group & 183 & 4.27 & .606 & \multirow{2}{*}{$6.513^{* * *}$} & \multirow{2}{*}{.000} \\
\hline & diversity & Control group & 111 & 3.69 & .800 & & \\
\hline & Col cotting & Experimental group & 183 & 3.67 & .896 & \multirow{2}{*}{$2.418 *$} & \multirow{2}{*}{.016} \\
\hline & Gual seumg & Control group & 111 & 3.42 & .763 & & \\
\hline & Managing & Experimental group & 183 & 3.69 & .822 & \multirow{2}{*}{$4.516 * * *$} & \multirow{2}{*}{.000} \\
\hline & emotions & Control group & 111 & 3.25 & .778 & & \\
\hline & Making & Experimental group & 183 & 3.40 & .970 & \multirow{2}{*}{$4.006 * * *$} & \multirow{2}{*}{.000} \\
\hline & healthy choices & Control group & 111 & 2.98 & .796 & & \\
\hline & Helping others & Experimental group & 183 & 4.00 & .716 & \multirow{2}{*}{$4.288 * * *$} & \multirow{2}{*}{.000} \\
\hline & and getting help & Control group & 111 & 3.64 & .690 & & \\
\hline & Meeting and & Experimental group & 183 & 3.49 & .916 & \multirow{2}{*}{$3.533^{* * *}$} & \multirow{2}{*}{.000} \\
\hline & greeting & Control group & 111 & 3.10 & .892 & & \\
\hline
\end{tabular}

$* \mathrm{p}<.05, * * * \mathrm{p}<.001$ 


\section{Discussion}

The present study explored whether teachers' participation in the PD program caused differences in students' recognition of the learning climate and life skills transfer. The results showed that teachers' continuous participation in the PD program for one year created a class climate that supported students' autonomy and relatedness and strengthened their competencies. The program had impacts on students' perceptions of learning climate and life skills transfer. As indicated by Bechtel and O'Sullivan (2006), the effect of the program was influenced by design and content of the program. The design feature of Project Change Up included multiple components such as online pre-training, intensive workshop, monthly workshops, and mobile instant messenger chatroom activities. It enabled teachers to learn physical education teacher's profession by interacting with and learning from diverse components of the program. In addition, the pedagogical case-based discussion, lecture, micro-teaching, role playing, and collective lesson planning facilitated teachers' collaborative, reflective, and collegial learning (Betchel \& O'Sullivan, 2006; Casey, 2013; Parker, Patton, \& Tannehill, 2012). The broad spectrum of program content such as integrating life skills into content knowledge, pedagogical content knowledge to support for teachers in the beginning stage, lesson case study, and observing other teachers' classes have facilitated participants' contextualized understanding of life skills implementation, which supports characteristics of effective PD program (Murphy \& O'Leary, 2012; Sinelnikov, 2009). Thus, physical education teachers learned specific pedagogical methods and applied it to their teaching practices for promoting students' PYD. The majority of physical education teachers recognize the importance of PYD but they experience difficulties with practical methods (Lee et al., 2018), and the results of the present study showed that effective PD can resolve such difficulties.

Second, a theory-based PD program for intentionally teaching life skills to teachers may increase the development and transfer of students' life skills. When teachers are systematically educated to teach life skills with the Basic Needs Theory (Deci \& Ryan, 2000) and the conceptual model of life skills development (Hodge et al., 2012), they can increase the development and transfer of life skills among students. In other words, physical activity does not automatically bring about the development of students' life skills; it should be supported by systematic and intentional educational activities directed by the teacher (Park, 2012; Shields $\&$ Bredemeier, 2005). In this study, school-based and continuous PD-rather than a one-shot, off-context, decontextualized PD-was effective in providing teachers with practical knowledge and theory for teaching life skills.

Third, this study has its significance in investigating the effect of teachers' continuous participation in PD from students' perspectives. Research on PD thus far (Lee et al., 2019) has been focused on the influence of PD participation on teachers. The ultimate goal of $\mathrm{PD}$, however, is not only improvement in teachers' knowledge, skills, and attitudes, but also the influence of such changes on teaching practice and, ultimately, contributions to student achievement (Lee et al., 2017). The present study has its significance in identifying the influence of teachers' PD participation on teachers' teaching behaviour, PE students' achievements by confirming that teachers' continuous participation in PD for one year changed the learning climate of students, and such changes brought about the development and transfer of life skills.

\section{Conclusion}

In this study, the effects of a year-long teacher PD program on the learning atmosphere recognized by students and the transfer of life skills were examined. Based on the present study, future research regarding teacher PD and life skills development is suggested, as described below. 
First, more researches are needed to test the influence of PD programs on the development and transfer of students' life skills in more detail, utilizing pre- and post-tests with the experimental and control groups. Findings will be helpful in explaining the effects of teacher PD programs more directly and with cause-and-effect relationships.

Second, research on the relationship between students' sports skills and sports learning methods and the corresponding development of life skills is needed. Considering that life skills are developed through sports participation and practice, such research is expected to provide teachers with specific strategies for choosing instructional methods, according to students' levels of sports skills, for the development of life skills.

Finally, research into the effects of PD programs in terms of changes in teachers, students and their relationship is needed. Most of previous studies investigated the influence of PD programs on teachers and students separately. Considering that PD programs can influence not only teachers and students but also the dynamic relationships between them, research investigating the effects of such complex interplay is needed in the future.

\section{Acknowledgments}

This work was supported by Global Research Network program through the Ministry of Education of the Republic of Korea and the National Research Foundation of Korea (NRF-2016S1A2A2912046).

\section{References}

Armour, K. M. (2017). Pedagogical cases: A new translational mechanism to bridge theory/research practice gaps in youth physical activity education (PAE). Kinesiology Review, 6(1), 42-50.

Armour, K. M., \& Makopoulou, K. (2012). Great expectations: Teacher learning in a national professional development programme. Teaching and Teacher Education, 28(3), 336-346.

Armour, K. M., \& Yelling, M. (2007). Effective professional development for physical education teachers: The role of informal, collaborative learning. Journal of teaching in physical education, 26(2), 177-200.

Casey, A. (2013). Practitioner research: A means of coping with the systemic demands for continual professional development?. European Physical Education Review, 19(1), 76-90.

Choi, E. (2010). Can sportsmanship be taught? -The difficulties and possibilities of teaching the affective domain in physical education-. Korean Journal of Sport Pedagogy, 17(1), 1-24.

Danish, S. (1995). Reflections on the status and future of community psychology. Community Psychologist, 28(3), 16-18.

Danish, S. J. (2002). SUPER (Sports United to Promote Education and Recreation) program leader manual. Richmond, VA: Life Skills Center, Virginia Commonwealth University.

Danish, S. J., Meyer, A., Mash, J., Howard, C., Curl, S., Brunelle, J., \& Owens, S. (1998). Going for the goal: Student activity book. Richmond, VA: Virginia Commonwealth University.

Goodyear, V. A. (2017). Sustained professional development on cooperative learning: Impact on six teachers' practices and students' learning. Research Quarterly for Exercise and Sport, 88(1), 83-94.

Gould, D., \& Carson, S. (2008). Life skills development through sport: current status and future directions. International Review of Sport and Exercise Psychology, 1(1), 58-78.

Hodge, K., Danish, S., \& Martin, J. (2012). Developing a conceptual framework for life skills interventions. The Counseling Psychologist, 41(8), 1125-1152.

Holt, N. L. (2016). Positive youth development through sport. New York: Routledge.

Kerrick, J. (2015). The transformative effect of youth sports: Forging an intentional path towards enriching children's lives through sports. Phoenix, 
AZ: Jones Media Publishing.

Lee, O., Choi, E., Jung, H., \& Yoon, K. (2017). A systematic review of physical education teachers' continuing professional development. Korean Journal of Sport Pedagogy, 24(3), 1-23.

Lee, O., Choi, E., Son, H., Jung, H., \& Jo, K. (2019). Exploring the development and optimization process of a professional development program for life skills teaching-oriented PE classes. Journal of Research in Curriculum and Instruction, 23(4), 335-345.

Lee, O., Yoon, K., Choi, E., Son, H., Jung, H., \& Lee, K. (2018). How is positive youth development understood and practiced by Korean secondary physical education teachers? A broad picture. Journal of Physical Education and Sport, 18(4), 2240-2247.

Lee, O., Choi, E., Griffiths M., Goodyear V., Armour K., Son, H., \& Jung, H. (2019). Landscape of secondary physical education teachers' professional development in South Korea. Sport, Education and Society, 24(6), 597-610.

Lim, T., Bae, J., \& Jang, C. (2018). The Validation of Korean Life Skills Transfer Survey(KLSTS). Korean Society of Sport Psychology, 29(4), 1-12.

Ministry of Education. (2015). Korean national curriculum of physical education. Sejong: Korean Ministry of Education.

Murphy, F., \& O'Leary, M. (2012). Supporting primary teachers to teach physical education: continuing the journey. Irish Educational Studies, 31(3), 297-310.

Park, J. (2012). Empirical research on the developmental Level and domain of sportsmanship: Middle school PE classes. The Journal of Curriculum Studies, 30(3), 221-246.

Ryan, R. M. \& Deci, E. L. (2000). The darker and brighter sides of human existence: Basic psychological needs as a unifying concept.
Psychological Inquiry, 11, 319-338.

Shields, D. \& Bredemeier. B.(2005). Can sports build character?. In D. Lapsley, C. Power(Eds.), Character Psychology and Character education(pp. 121-139). Indiana: University of Notre Dame Press. Sinelnikov, O. A. (2009). Sport education for teachers: Professional development when introducing a novel curriculum model. European Physical Education Review, 15(1), 91-114.

Standage, M., Duda, J. L., \& Ntoumanis, N. (2005). A test of self-determination theory in school physical education. British Journal of Educational Psychology, 75(3), 411-433.

Turnnidge, J., Côté, J., \& Hancock, D. J. (2014). Positive youth development from sport to life: Explicit or implicit transfer? Quest, 66, 203-217.

Walker, J., Marczak, M., Blyth, D., \& Borden, L. (2005). Designing youth development programs: Toward a theory of developmental intentionality. In J. L. Mahoney, R. W. Larson, \& J. S. Eccles (Eds.), Organized activities as contexts of development: Extracurricular activities, after-school and community program (pp. 399-418). Mahwah, NJ: Lawrence Erlbaum.

Weiss, M. R. (2006). The First Tee 2005 research summary: Longitudinal effects of the First Tee life skills educational program on positive youth development. St. Augustine, FL: The First Tee.

Weiss, M. R., Bolter, N. D., \& Kipp, L. E. (2014). Assessing impact of physical activity-based youth development programs: Validation of the Life Skills Transfer Survey (LSTS). Research quarterly for exercise and sport, 85(3), 263-278.

Williams, G. C., \& Deci, E. L. (1996). Internalization of biopsychosocial values by medical students: A test of self-determination theory. Journal of Personality and Social Psychology, 70(4), 767-779. 